\title{
IMPACT OF DEREGULATION OF THE JAMAICA MOBILE PHONE MARKET ON CALLING RATES
}

\author{
Abdullahi O. Abdulkadri \\ Department of Economics, The University of the West Indies, Mona Campus, Kingston 7, Jamaica
}

Received 2014-06-26; Revised 2014-06-28; Accepted 2014-08-25

\begin{abstract}
Deregulation of the telecommunications industry has led to a phenomenal growth in mobile phone service subscription in Jamaica with penetration rate reaching more than $100 \%$ within a decade of the start of deregulation. Consumers have benefited with significant cuts in rates for mobile phone service following the entry of new service providers. This study models the competition among old and new service providers as a game of entry deterrence in which the entrant is of two types, a low-cost or a high-cost entrant. The entrant knows its type but the incumbent does not. However, the incumbent knows the probability that nature assigns to a particular type of entrant. Four scenarios are examined as candidates for equilibrium. In the first scenario, our model shows that the incumbent can ensure that a new entrant stays out by setting price too low. In scenario two, regardless of the action of the incumbent, the low-cost entrant will always enter the market and the incumbent will cooperate. For scenario three, the incumbent's action to fight an entrant will only make the high-cost entrant to stay out if price is set too low or cost is too high. In the final scenario, the entrant will always enter regardless of its type and the incumbent will have no other choice than to cooperate. In the case of the Jamaica mobile phone market, our model suggests that the only Bayesian Nash equilibrium is a separating equilibrium in which the incumbent fights entry and the low-cost entrant enters the market. In equilibrium, the price war between old and new companies will persist until all economic profits have been eroded, potentially setting the stage for a return to monopoly. However, even under a monopoly, the low rates for service will persist as the incumbent has a strong incentive to keep prices low to deter any potential new entrants. Based on our model results, we conclude that incumbent mobile phone service providers in Jamaica will continue to institute a price war and a new provider will enter the market only if it has superior technology or a strong financial base.
\end{abstract}

Keywords: Entry Deterrence, Deregulation, Industry Leader, Jamaica, Price War

\section{INTRODUCTION}

The deregulation of the telecommunications industry in Jamaica has had a profound impact on the mobile phone market in the country. The Government of Jamaica (GOJ) began the deregulation process with the signing of an agreement with the monopoly telecommunications company, Cable and Wireless Jamaica Limited (C\&WJ) in September 1999. As at that time, C\&WJ maintained a monopoly power for telephone and internet services in the island. Mobile phone service was limited with some 120,000 subscribers representing less than $5 \%$ penetration rate in a country of about 2.6 million people. By 2007, a $100 \%$ penetration rate had been achieved and the subscription base continued to grow reaching $117 \%$ in 2010 (OUR, 2012).

In less than a decade of operating in a deregulated market, the Jamaica mobile phone market had indeed captured the interests of many stakeholders. In addition to the phenomenal growth recorded in mobile service subscription since deregulation, liberalization resulted in improved service at cheaper rates for consumers. The government also generated lucrative revenues from the auctioning of licenses to prospective service providers while the economy benefitted from significant investments by service providers who explored and 
continue to explore better technologies to deliver their products and services.

However, in recent times, there are concerns that the highly competitive market may have created a conducive environment for the return to monopoly. Although the original monopoly company went from having a total control of the market in 2000 to just a $20 \%$ share in 2006, within that period, Digicel, one of the new companies, had grown to control $76 \%$ of the market share (FTC and OUR, 2007). Digicel's current market share is believed to be in excess of $80 \%$. While the government continues to aggressively promote competition in the telecommunications industry with auctioning of new spectrum licenses, results of recent auctions have been disappointing. The government was forced to negotiate with incumbent companies to acquire these licenses when the last auction did not attract any bids from new companies. Meanwhile, the incumbent companies continue to engage in a "price war" to gain new customers or at least maintain existing ones. While observers see this as a healthy competition for the benefit of the consumers, there are also genuine concerns that in the current duopoly market, the exit of the old monopolist for any reason will lead to a return to monopoly and the end of low prices that consumers currently enjoy.

In this study, we set out to examine the dynamics of the mobile phone service market in Jamaica using game theory. Specifically, we queried that given the trend already observed in the market, should consumers expect further cuts in rates if the incumbent providers continue to wage a price war against each other or new entrant(s)? Or will it be in the interests of the incumbents and an entrant not to engage in price war? What if the market returns to a monopoly, will that lead to an increase in prices paid by consumers? These and other questions are answered using a game theoretic model of entry deterrence. The model is used to analyze the equilibrium actions of mobile phone service providers in Jamaica with the overarching objective of providing economic rationales for the observed behaviors of service providers. It also offers a basis for forecasting what to expect in the mobile phone market in the near future in relation to prices paid by consumers.

Following the introduction, the next section provides a brief historical background of the mobile phone service market in Jamaica. This is followed by a theoretical overview of game of entry deterrence. The analytical model is then presented followed by the results. The implications of the results are discussed in the next section and the paper concludes with a summary of the findings.

\section{DEREGULATION OF THE TELECOMMUNICATIONS INDUSTRY IN JAMAICA}

The deregulation of the telecommunications industry in Jamaica was implemented in stages with specific targets set for each phase. Following the promulgation of the Telecommunications Act in March 2000, Phase I took effect in April 2000 and enabled the opening up of the market to competition in mobile services, the provision of customer equipment, the resale of data, international voice and internet access and allowing companies with single entity free zone status to provide their own telecommunications services. Phase II began in September 2001 and covered competition in domestic facilities and services and permitted cable television providers to become internet service providers. The final phase, Phase III, commenced in April 2003 and allowed the opening up of all telecommunications facilities to competition, including international voice and data services (GOJ, 2002; FTC and OUR, 2007).

After the successful implementation of Phase I, two mobile service operators, Centennial Communications (51\% ownership)/Oceanic Digital Jamaica (49\% ownership (trading as MiPhone) and Mossel Ltd. (trading as Digicel) emerged as new competitors to the incumbent monopolist, C\&WJ. The auctioning of spectrum licenses to these two companies generated US\$92.5 million for the government (Golding et al., 2011). In addition, more than US\$1 billion was invested in capital expenditure by the three companies during the first five years of liberalization (FTC and OUR, 2007). These investments by the firms have resulted in improvements in service delivery and greater customer reach. The rate of growth in mobile service penetration has been particularly intriguing, driven primarily by Digicel's rapid rise from a new player in the market in 2001 to becoming the dominant player in just a year. The rapid take up of mobile phone service subscription impacted negatively on fixed-line service subscription. It was estimated that about 50,000 fixed-line service subscribers discontinued their subscription between December 2002 and April 2003 (Observer, 2003). The competition in the mobile service market led to lower rates for consumers on domestic and international calls, not only on mobile phones but also on fixed lines. For example, the per minute rate charged by $\mathrm{C} \& \mathrm{WJ}$ for calls to the United States (US) fell from J\$30 to J\$18 in 2002. By 2007 , the rate had further declined to J\$15.75 per minute for calls made from fixed lines and to as low as 
J\$14.50 per minute for calls made from mobile phones (FTC and OUR, 2007). Depending on service provider and the plan chosen, current rate for calls to fixed lines in the US, Canada and the United Kingdom (UK) could be as low as $\mathbf{J} \$ 2.99$ per minute while local calls could be as low as $\mathrm{J} \$ 2.49$ per minute for pre-paid customers.

This price incentive ushered in by competition among service providers has boosted demand for mobile phone services. The competition has also engineered a rather rapid reorganization of the market. Within a year of acquiring the license to operate, the minority owner of MiPhone, Oceanic Digital Communications, acquired $100 \%$ stake in the company and embarked on a reorganization exercise. With the reorganization of the new company, MiPhone laid off some of its staff. In a surprise move, Digicel absorbed many of the former MiPhone staff in its ongoing effort to expand operations in the island and establish itself as the dominant player. In March 2004, AT\&T, a major player in the US telecommunications industry, acquired the fourth license to operate mobile phone services in Jamaica at a price of US\$6 million, which was just a fraction of what was paid by the first entrants to the market. The expected entrance of AT\&T generated a lot of excitement in the industry but this never materialized as AT\&T, after being acquired by Cingular Wireless, never commenced operation in Jamaica even though it procured the license.

Although AT\&T failed to operate in Jamaica, another major player in South America, America Movil (trading as Claro) acquired MiPhone and began a new kind of fierce competition, mainly with Digicel. By this time Digicel had effectively taken over the market as the new "industry leader" and had started expanding to other Caribbean and Latin American countries. Claro's entry in the Jamaican market was perceived as a retaliatory move by Claro for Digicel's entry in those markets in Latin America that had traditionally been under Claro's control. In a fight for survival, C\&WJ in 2008 embarked on an expansive rebranding that included a name change to Landline, Internet, Mobile and Entertainment (LIME). With some US\$30 million spent on network upgrade as part of its rebranding exercise and no immediate rise in subscriber base, LIME suffered financial losses following the rebranding. Meanwhile, Digicel and Claro's fierce price competition was short-lived with the announcement of a merger of the two companies. The merger, which was completed in November 2011, resulted in Digicel acquiring Claro's operation in Jamaica. In return, Claro assumed ownership of Digicel's operations in El Salvador and Honduras. This merger effectively introduced a duopoly in the Jamaica mobile phone market for the first time.
The Digicel/Claro merger was seen as a set-back for liberalization and many called for the regulator to block the merger. However, the Office of Utilities Regulation (OUR), which has regulatory oversight for the telecommunications industry approved the merger despite oppositions from LIME and the Fair Trading Commission (FTC). Many stakeholders shared the concerns of these two entities that although the merger would result in a duopoly, the acquisition would make Digicel so dominant that it can act with monopoly powers. The government, however, has not wavered in its commitment to a liberalized market that encourages competition and continues to pursue the auctioning of new spectrum licenses. In February 2009 and October 2013, new spectrum auctions conducted by the government did not yield expected results with the only bid received in 2009 rejected by the Spectrum Management Authority (SMA) for being below the reservation price while no bids were received for the 2013 auction despite interests shown by 24 entities from 10 countries in the public forum that preceded the auction. Eventually, the government was forced to negotiate with the incumbent service providers to acquire these licenses with Digicel paying US\$25 million for a $700 \mathrm{MHz}$ spectrum block that the government had hoped to receive US\$45 million for in an auction.

This type of "power of incumbency" exhibited by the dominant player in the mobile phone market is what stakeholders fear may enable Digicel to squeeze LIME out of the market and prevent other would-be entrants from ever taking off. However, LIME has not given-in yet. In its financial report for year ending March 2014, LIME reported a $7 \%$ gain in mobile phone market share with a $31 \%$ growth in subscription by some 165,000 new customers to reach 705,000 customer base (Brown, 2014). While this represents a huge increase for an erstwhile monopolist, it reflects how the customer base of LIME had been eroded by Digicel/Claro merger and the strategic pricing behavior of Digicel. To achieve this feat, LIME had to engage in an aggressive pricing strategy of its own with an enticing low rate of J\$2.99 per minute that applies to in-network, outside-network and international calls (to fixed lines in US, Canada and UK). This compared favorably to Digicel's best rate of J\$2.49 that applied only to mobile numbers on the two networks. However, in this dynamic price war environment, Digicel extended the $\mathrm{J} \$ 2.49$ rate to calls terminating on any network with effect from June 2014.

Prior to the aggressive push by LIME and the recent counter move by Digicel, Digicel had effectively shut 
LIME out of the market by offering a low rate for innetwork calls and a much higher rate for out of network calls. With its dominant share of the market and the nonexistence of number portability in Jamaica, such a strategy is in fact profitable for Digicel as it reduces, if not eliminates, the incentive for existing customers to switch to LIME. On the other hand, it encourages, if not forces, LIME customers to subscribe to Digicel services. The radical overhaul of LIME's pricing strategy at least offers some incentives for existing customers to maintain their subscription while holding prospects for encouraging new customers to sign up. However, it is too early to tell if LIME will be able to sustain the new inroads it is making in terms of growth in subscription to its mobile phone service given the readiness shown by Digicel to cut price further.

\section{GAME OF ENTRY DETERRENCE}

GOJ's actions have signaled the willingness to keep the mobile phone market liberalized, leaving open the possibility that more licenses will be auctioned in the near future. This keeps open the prospect for new mobile service providers to enter the Jamaica mobile phone market. In such a circumstance, as was the case in the early years of deregulation, the incumbent(s) and the entrants are continuously engaged in a game of entry deterrence and every player must make strategic decisions to maintain profitability, in the case of an incumbent, or to attain viability, in the case of an entrant. These strategic interactions of agents are best analyzed using game theory.

Game theory remains a very relevant tool for analyzing behaviors of economic agents, especially in the field of industrial organization where models of entry deterrence are widely used to explain why a firm with monopoly power may wage a price war against a new firm entering the market. Neven (1989) provided a detailed review of developments, as at that time, in the economics of industry in relation to strategic entry deterrence. Since then, several other studies have been published focusing on different aspects of entry deterrence models and its application.

Clark and Montgomery (1998) examined how an incumbent's competitive reputation with a potential entrant in a certain market may serve as deterrence for entry in another market in a multi-market competition. Their study showed that an incumbent's reputation for aggressiveness but not intelligence makes a market less attractive and more risky to a potential entrant.
Along the same line, Iozzi (2001) showed that dynamic price-cap regulation permits a regulated firm to deter entry by setting a low price before a potential entrant enters thereby committing itself to charging a low price in the event of entry. Jaag (2011) also noted that a credible threat to behave aggressively, which could be in the form of heavy investment in capacity or setting of a low price, represents the most important ingredient to entry deterrence.

Jain et al. (2003) employed a dynamic model with asymmetric information to analyze the interaction between an incumbent's financial contract with a bank and its product market decisions when faced with a threat of entry. They found that a separating equilibrium exists without a pricing limit wherein the low-cost incumbent repays more to the bank in the first period.

Gangopadhyay et al. (2011) used an interactive model of fiscal gaming in examining economic misgovernance. In their model, a welfare-maximizing central government sets the local taxes given the diversion of funds by the local government and the local government chooses the level of diversion of funds to maximize its payoff given the local taxes and intergovernmental transfers. They argued that the resultant Nash equilibrium entails the combination of taxes and diversion of funds that are self-confirming.

Specifically focusing on the telecommunications industry, Koski and Majumdar (2002) investigated the impact of the presence of new competitors on the pricing behaviors of U.S. Incumbent Local Exchange Carriers (ILECs). While their work documented the existence of vigorous entry, they noted that the incumbents still maintained substantial market share through strategic behavior to deter entrance.

Many other studies using models of entry deterrence have examined the role of multiple potential entrants in non-cooperative games (Waldman, 1991), what happens when a network good is priced in order to deter entry (Fudenberg and Tirole, 2000) and the relationship between strategic behavior to deter entry and quality provision (Van Der Veer, 2002). Others have applied models of entry deterrence to analyze strategic behaviors in congressional elections (Dharmapala, 2002), the influence of size on strategic behavior of pharmaceutical companies facing patent expiration (Ellison and Ellison, 2011), the strategic interaction between entry cost and quality limit under minimum quality standards (Lee and Phuyal, 2013), strategic entry barriers for business enterprises in Singapore (Chang and Tang, 2001), the strategic reaction of private firms to threat of entry by 
public firms (Seamans, 2012) and entry deterrence in the airline industry (Aguirregabiria and Ho, 2010).

\section{ANALYTICAL MODEL}

Our model is set as a tool to analyze the actions of mobile service providers during the first phase of deregulation of the telecommunications industry in Jamaica. Later, the model is used to predict future actions of remaining firms after deregulation has taken root. The model is based on the assumption that the incumbent service providers are individually and collectively faced with the decision to deter prospective service provider(s) from entering the market by reducing or keeping low the prevailing rate charged on mobile phone calls or to cooperate with the new service provider by maintaining rate and sharing the customer base. A prospective service provider also has to definitively decide if it will begin operations regardless of what the incumbent service providers do or drop out from the market fearing the threat of lower prices in the event that it enters the market.

We introduce realism into the model by assuming asymmetric information in which a prospective entrant could be of two types, a low-cost entrant or a high-cost entrant. In the case of two or more incumbents, the model provides for the provider with the largest market share to act as an industry-leader and its pricing strategy is followed by the other incumbents.

Nature assigns probabilities to the two types of entrants. The entrant, fully aware of its type and given the prevailing mobile service call rates, makes an entry decision. The incumbents, unaware of the type of the entrant, then move to review their pricing decisions. The payoffs to the players depend on the strategy combination and the probability that nature assigns to each type of entrant.

Let $\theta_{L}$ be the probability that nature assigns to a lowcost entrant and $\theta_{H}$ be the probability that nature assigns to a high-cost entrant. Let $C_{L}$ and $C_{H}$ be the per unit operating costs that an entrant incurs when it is of a lowcost and high-cost type, respectively. If the entrant is faced with price war from the incumbents, it bears an additional unit cost $x$ that is independent of type. For both the incumbents and the entrant, the price they receive per unit of service rendered is uniform and equals to $P_{C}$ if the incumbents cooperate with the entrant and maintain rates or $P_{F}$ if the incumbents fight the entrant by reducing rates. The incumbents are assumed to have lower operating costs than the entrant, at least in the short run and these costs are normalized to zero. Likewise, the entrant's payoff, in the situation that it decides not to enter the market is set to zero. The configuration of the strategies and payoffs is given in Table 1. The values of the payoffs are determined according to the following restrictions: $P_{C}>P_{F}, C_{H}>C_{L}$ and $x>0$ In addition, nature assigns probability to the type of entrant with the condition that $\theta_{H}+\theta_{L}=1$.

Four different scenarios are specified in order to examine the equilibrium outcome(s) of the game. The first scenario is when total unit cost to the low-cost entrant is higher than the unit price it receives if the entrant chooses to fight $\left(C_{L}+x>P_{F}\right)$. Scenario two is when the total unit cost to the low-cost entrant is at most equal to the unit price if the incumbent chooses to fight $\left(C_{L}+x \leq P_{F}\right)$. Scenario three represents the situation where the total unit cost to the high-cost entrant is higher than the unit price it receives should the entrant choose to fight $\left(C_{H}+x>P_{F}\right)$ and finally, scenario four is when the total unit cost to the high-cost entrant is at most equal to the price it receives if the incumbent decides to fight $\left(C_{H}+x \leq P_{F}\right)$. For the purpose of our analysis, we assume that an incumbent uses passive conjecture by basing its belief on the prior probabilities.

Once the beliefs are formed, the incumbent, unaware of the entrant's type, must evaluate the outcome of the game based on the expected payoffs. The entrant, on the other hand, knows its type and evaluates the outcome based on the actual payoff it hopes to receive from a strategy combination. A perfect Bayesian equilibrium is hence achieved when a strategy combination and the set of beliefs of the uninformed player result in a Nash equilibrium.

Table 1. Strategy and payoff configuration for the entrant and the incumbent in the Jamaica mobile phone market

\begin{tabular}{|c|c|c|c|c|c|}
\hline & \multirow[b]{3}{*}{ Strategy } & \multicolumn{4}{|c|}{ Entrant } \\
\hline & & \multicolumn{2}{|l|}{ High-cost type } & \multicolumn{2}{|l|}{ Low-cost type } \\
\hline & & Enter & Stay out & Enter & Stay out \\
\hline Incumbent & $\begin{array}{l}\text { Fight } \\
\text { Cooperate }\end{array}$ & $\begin{array}{l}\mathrm{P}_{\mathrm{F}}, \mathrm{P}_{\mathrm{F}}-\mathrm{C}_{\mathrm{H}}-\mathrm{x} \\
\mathrm{P}_{\mathrm{C}}, \mathrm{P}_{\mathrm{C}}-\mathrm{C}_{\mathrm{H}}\end{array}$ & $\begin{array}{l}\mathrm{P}_{\mathrm{F}}, 0 \\
\mathrm{P}_{\mathrm{C}}, 0\end{array}$ & $\begin{array}{l}\mathrm{P}_{\mathrm{F}}, \mathrm{P}_{\mathrm{F}}-\mathrm{C}_{\mathrm{L}}-\mathrm{x} \\
\mathrm{P}_{\mathrm{C}}, \mathrm{P}_{\mathrm{C}}-\mathrm{C}_{\mathrm{L}}\end{array}$ & $\begin{array}{l}\mathrm{P}_{\mathrm{F}}, 0 \\
\mathrm{P}_{\mathrm{C}}, 0\end{array}$ \\
\hline
\end{tabular}




\section{RESULTS}

\subsection{Scenario One $\left(C_{L}+x>P_{F}\right)$}

The expected payoff to the incumbent when it chooses fight $\left(P_{F}\right)$ is less than the expected payoff when it chooses cooperate $\left(P_{C}\right)$, so it is more profitable for the incumbent to choose to cooperate. As for the low-cost entrant, its payoff will be negative if the incumbent chooses to fight entry but may be positive if the incumbent chooses to cooperate (so long as $P_{C}$ is high enough or $C_{L}$ is low enough). The payoff to the entrant is zero if it stays out. Hence, the incumbent can ensure that the entrant stays out by setting $P_{C}$ too low and in such case the entrant will choose stay out.

\subsection{Scenario Two $\left(C_{L}+x \leq P_{F}\right)$}

The expected payoff to the incumbent when it chooses fight is still less than the expected payoff when it chooses cooperate. As for the low-cost entrant, its payoff is now strictly non-negative regardless of the move taken by the incumbent. Therefore, enter is at least a weakly dominant strategy for the entrant. Therefore, the low-cost entrant will always enter and the incumbent will cooperate. This will arise when $P_{F}$ is set too high or $C_{L}$ is too low, signifying a strong entrant.

\subsection{Scenario Three $\left(C_{H}+x>P_{F}\right)$}

As was the case in the last two scenarios, the expected payoff to the incumbent when it chooses fight is less than the expected payoff when it chooses cooperate. If the incumbent chooses to fight a high-cost entrant, the entrant's payoff will be negative if it enters and zero if it stays out. However, if the incumbent always cooperates with an entrant upon noticing entry since it cannot tell the type of the entrant, then the highcost entrant, although inefficient, will also enter in anticipation of cooperation, resulting in a positive payoff. Hence, the separating equilibrium in which only the low-cost entrant enters and the high-cost entrant stays out will only result when the incumbent fights any entrant by setting $P_{F}$ too low or when the entrant is highly inefficient with a very high $C_{H}$.

\subsection{Scenario Four $\left(C_{H}+x \leq P_{F}\right)$}

Again here, the expected payoff to the incumbent when it chooses fight is less than the expected payoff when it chooses cooperate. The high-cost entrant earns a non-negative payoff if it enters regardless of what the incumbent does, so entering is at least a weakly dominant strategy. Under this scenario, we would expect a pooling equilibrium in which both types of entrant enter and the incumbent cooperates. This will result when $P_{F}$ is too high.

\subsection{Bayesian Nash Equilibrium}

Considering the four scenarios specified, a pooling equilibrium is ruled out in scenario one, while scenarios two and four support a pooling equilibrium in which both low cost and high cost entrants would enter the market. Only scenario three guarantees a separating equilibrium in which only the low-cost entrant enters the market. In analyzing the strategy combinations, we can observe that the threat of a fight is credible under scenarios one and three but not credible in scenarios two and four. The threat of a fight ensures that both the lowcost and high-cost entrants stay out in scenario one. In scenario three though, the threat of a fight is only effective in keeping the high-cost entrant out of the market. Since the threat of a fight is not credible in scenarios two and four, we would expect both the lowcost and high-cost entrants to enter the market.

Of the four scenarios considered, only scenario three fits the sequence of events and the outcome of the initial years of deregulation in the Jamaica mobile phone market. In scenario one, we would have expected no new service provider to enter the market but two companies did and offered mobile services ruling out that scenarios as the applicable one. That suggests that $P_{C}$ was not too low and there were economic profits being derived by $\mathrm{C} \& \mathrm{WJ}$ as the monopolist. In the case of scenario two, we noticed that there were early exits, mergers and acquisitions in the market, suggesting that $P_{F}$ was not too high, although $C_{L}$ may as well have been very low. The same argument of non-existence of a too high $P_{F}$ could be used to rule out scenario four in which a high-cost entrant would have entered the market. That leaves us with scenario three in which only the low-cost entrant, Digicel, MiPhone (and then Claro) entered the market. Thus, a separating equilibrium emerged as a result of deregulation in which the low-cost entrants Digicel (due to its superior technology) and MiPhone (as a result of its niche market strategy) were the only successful entrants. This was only ensured by C\&WJ's commitment to "fight" as a strategy and to establish a reputation for doing so to deter other would-be entrants.

\section{DISCUSSION}

By choosing to fight the first generation of entrants, $\mathrm{C} \& \mathrm{WJ}$, the incumbent monopolist, established a reputation for being a "fighter" and this threat to fight 
entry was taken seriously by future entrants who were ready, to varying degrees, for the fight. Also, by establishing this reputation, the incumbent effectively deterred the high-cost entrants, who otherwise would be tempted to enter in anticipation of the incumbent's cooperation. Nonetheless, choosing to fight did nothing to deter the low-cost entrants who operated profitably, with Digicel dominating the market within a year of entry. As the new market leader, Digicel has continued to play the entry deterrence game as exemplified in Claro's exist from the market after a takeover of MiPhone and the refusal of any new entrant to take up the government's offer of new licenses through its auctions.

These actions are consistent with the findings of Iozzi (2001) who found that dynamic price-cap regulation permits a firm to deter entry by setting sufficiently low price and that the effectiveness of this strategy depends on the entry cost of the entrant, the tightness of the price cap and the market power that the competing firms command. Apart from the absence of a price-cap regulation, all other conditions apply to the Jamaica mobile phone market. Although OUR does not implement a price-cap for telecommunications firms in Jamaica, a firm can selfimpose a price-cap in order to achieve the same result that a price-cap regulation will produce.

Market power has also been noted as an important factor in the entry deterrence behavior of ILECs in the US. Koski and Mujumdar (2002) found that while ILECs, in general, did not use aggressive access pricing strategy to deter entry by Competitive Local Exchange Carriers (CLECs), the larger ILECs did charge significantly higher access prices for calls on their network, effectively reducing the profit margin for CLECs and their competitiveness in the local telephone market. Both C\&WJ and Digicel enjoyed market power at different times and used this strategically to dominate the market but with different end results. This shows that while an incumbent may possess the market power advantage, it does not guarantee that the firm will be successful in using it to deter new entrant. An early mover advantage may in fact prove more beneficial. Digicel enjoyed this early mover advantage with the introduction of its Global System of Mobile (GSM) Communications technology. The early mover advantage enjoyed by Digicel has also been observed in the European mobile phone market. Bijwaard et al. (2008) attributed this to the influence of the penetration rate. Digicel, by rapidly growing its customer base, was able to capitalize on the low penetration rate that hitherto existed in Jamaica.
However, with LIME hanging tough, the entry deterrence game, while being effective in keeping new entrants from the market, is also ensuring that prices paid by consumers remain low. Should LIME exit the market or become an ineffective competitor against Digicel, there should be little or no concerns that prices paid by consumers will rise. In fact, prices may drop further as Digicel could pursue a strategy to consolidate its grip on the market and conclusively exclude any viable competition by keeping prices artificially low. Consumers and indeed the regulators should be more concerned about other areas of service that may be impacted, such as quality of service and variety of plans that may suffer under a monopoly. As our model shows, scenario three is very effective in excluding high-cost or inefficient companies from entering the market and Digicel, having used the strategy of a low $P_{F}$ that ensures this scenario with successful outcome, will have no incentives to change strategy. Moreover, there is always the possibility that a really low-cost entrant may find it profitable to enter the market at some point. To reduce the probability of this happening, Digicel will keep prices low for as long as it can hang on to its dominance and, possibly, capture of the mobile phone market in a return to monopoly. This strategy is consistent with Patokos (2005) who showed that the optimal strategy for rational agents is to act aggressively when faced with opponents whose type they do not know with certainty. Therefore, in the operating environment of the Jamaica mobile phone market, a price hike is very unlikely even under a monopoly as the incumbent will price aggressively to deter entry.

\section{CONCLUSION}

In the game of entry deterrence being played by mobile phone service providers in Jamaica, we expect the incumbent(s) to institute a price war against any entrant. Since the companies are unable to make binding agreement not to lower prices (either due to the illegality of such an action or the non-enforceability of such an agreement), colluding to maintain prices will not be an equilibrium strategy for the incumbent companies if they anticipate the game to be repeated in the future. On the other hand, the optimal strategy for a prospective mobile phone service provider is to enter if it has superior technology that will translate to lower costs or a strong financial base to absorb initial losses and for it to stay out if it can only operate at a loss or with marginal profits under a price war. Hence, incumbent providers will keep fighting new entrants until all economic profits 
have been eroded, thus leading to a stage where it is suboptimal for any new company to enter the market. It is yet to be seen if the mobile phone market in Jamaica has reached such a stage but it is safe to expect that even when that stage is reached, prices paid by consumers will remain low as the incumbent or incumbents stave off potential competitors with a persistent price war.

\section{ACKNOWLEDGEMENT}

I am grateful to anonymous journal reviewers for helpful comments and suggestions. I am solely responsible for the contents of this study and any remaining errors.

\section{REFERENCES}

Aguirregabiria, V. and C.Y. Ho, 2010. A dynamic game of airline network competition: Hub-and-spoke networks and entry deterrence. Int. J. Industrial Org., 28: 377-382. 10.1016/j.ijindorg.2010.03.003

Bijwaard, G.E., M.C.W. Janssen and E. Maasland, 2008. Early mover advantages: An empirical analysis of European mobile phone markets. Telecommun. Policy, 32: 246-261. DOI: 10.1016/j.telpol.2007.08.006

Brown, R., 2014. Bittersweet returns from LIME Jamaica-subscriber base expands, but revenue shrinks. The Gleaner.

Chang, H.L. and F. Tang, 2001. An empirical study on strategic entry barriers in Singapore. Asia Pacific J. Manage., 18: 503-517. DOI: 10.1023/A:1012827410145

Clark, B.H. and D.B. Montgomery, 1998. Competitive reputations, multimarket competition and entry deterrence. J. Strategic Market., 6: 81-96. DOI: 10.1080/09652549800000002

Dharmapala, D., 2002. Campaign war chests, entry deterrence and voter rationality. Econom. Polit., 14: 325-350. DOI: 10.1111/1468-0343.00110

Ellison, G. and S.F. Ellison, 2011. Strategic entry deterrence and the behavior of pharmaceutical incumbents prior to patent expiration. Am. Econom. J. Microeconom., 3: 1-36.

FTC and OUR, 2007. A review of the Jamaican telecommunications sector. Fair Trading Commission (FTC), Kingston, Jamaica.

Fudenberg, D. and J. Tirole, 2000. Pricing a network good to deter entry. J. Industrial Econom., 48: 373390. DOI: $10.1111 / 1467-6451.00129$
Gangopadhyay, P., N. Elkanj and M.A. Rahman, 2011. Application of theories of complexity and chaos to economic misgovernance. J. Math. Stat., 7: 239-248. DOI: 10.3844 /jmssp.2011.239.248

Golding, P., V. Tennant and T. Virtue, 2011. Telecommunications in Jamaica: Monopoly to liberalized competition to monopoly (2000-2011). University of Technology.

GOJ, 2002. Telecommunications Policy. Ministry of Industry, Commerce and Technology. Government of Jamaica (GOJ), Kingston, Jamaica.

Iozzi, A., 2001. Strategic pricing and entry deterrence under price-cap regulation. J. Econom., 74: 283-300. DOI: $10.1007 / \mathrm{BF} 01231351$

Jaag, C., 2011. Entry deterrence and the calculation of the net cost of universal service obligations. Revi. Netw. Econom. DOI: 10.2202/1446-9022.1189

Jain, N., T.D. Jeitschko and L.J. Mirman, 2003. Financial intermediation and entry-deterrence. Econom. Theory, 22: 793-815. DOI: 10.1007/s00199-002-0351-2

Observer, J., 2003. Jamaicans giving up land phones.

Koski, H.A. and S.K. Majumdar, 2002. Paragons of virtue? Competitor entry and the strategies of incumbents in the U.S. local telecommunications industry. Inform. Econom. Policy, 14: 453-80. DOI: 10.1016/S0167-6245(02)00066-5

Lee, S.H. and R.K. Phuyal, 2013. Strategic entry deterrence by limiting qualities under minimum quality standards. Jap. Econom. Rev., 64: 550-563. DOI: $10.1111 /$ jere. 12007

Neven, D.J., 1989. Strategic entry deterrence: Recent developments in the economics of industry. J. Econom. Surveys, 3: 213-33. DOI: 10.1111/j.14676419.1989.tb00068.x

OUR, 2012. Annual Reports and Financial Statements 2011-2012. Office of Utilities Regulation (OUR). Kingston, Jamaica.

Patokos, T., 2005. On the evolutionary fitness of bounded rationality: Heterogeneous populations in antagonistic interactions. Am. J. Applied Sci., 2: 113. DOI: 10.3844 /ajassp.2005.1.13

Seamans, R.C., 2012. Fighting city hall: Entry deterrence and technology upgrades in Cable TV markets. Manage. Sci., 58: 461-475. DOI: $10.1287 / \mathrm{mnsc} .1110 .1440$

Van Der Veer, J.P., 2002. Entry deterrence and quality provision in the local bus market. Transport Rev., 22: 247-265. DOI: 10.1080/01441640110115092

Waldman, M., 1991. The role of multiple potential entrants/sequential entry in noncooperative entry deterrence. RAND J. Econom., 22: 446-453. DOI: $10.2307 / 2601058$ 